\title{
El mapa nacional en el aula de clase: Políticas de memoria y clases de geografía en el Ecuador (1875-1920) ${ }^{1}$
}

\section{Resumen}

En este artículo nos interesa pensar cómo se inventó la memoria oficial sobre el territorio ecuatoriano durante el siglo XIX e inicios del siglo XX. Trabajamos las prácticas de enseñanza de la geografía nacional a través de un estudio del contenido de los libros de geografía para niños que se emplearon en las escuelas entre 1875 y 1920. El artículo explora las maneras en las que el conocimiento geográfico migra desde los mapas nacionales hacia textos que, en principio, tienen una mayor posibilidad de circulación. Este elemento de circulación de la información geográfica es algo que típicamente no aparece en los trabajos sobre mapas nacionales y es un ángulo indispensable para enlazar el estudio de la geografía con su impacto en la construcción de la nación.

La tesis que planteamos es que los mapas y los paradigmas propuestos por los geógrafos, sus imágenes y sus perspectivas, fueron bien conocidos y circularon dentro de un público educado. En otras palabras, se hicieron parte del discurso público y sirvieron para que un grupo más importante de la población fuese capaz de imaginar el territorio compartido con el resto de habitantes y así crear a partir de los fundamentos geográficos un sentimiento de nacionalidad.

Palabras clave: Ecuador, geografía, nacionalismo, educación.

Referencia para citar este artículo: SEVILLA, Ana María (2016). "El mapa nacional en el aula de clase: Políticas de memoria y clases de geografía en el Ecuador (1875-1920)". En Anuario de Historia Regional $y$ de las Fronteras. 21 (2). pp. 47-73.

Fecha de recepción: 25/09/2015

Fecha de aceptación: 16/02/2016

Ana María Sevilla: Posdoctora en Historia de la Ciencia, Universidad de Leiden, Holanda. Doctora en Estudios Políticos, Facultad Latinoamericana de Ciencias Sociales (FLACSO), Ecuador. Profesora de Historia, Universidad San Francisco de Quito, Ecuador. Correo electrónico: anasevillaperez@gmail.com.

\footnotetext{
${ }^{1}$ Este artículo es resultado de mi investigación doctoral en FLACSO, Quito. Esta investigación se publicó en el 2013 bajo el título El Ecuador en sus mapas: Estado y nación desde una perspectiva espacial.
} 


\title{
The Country's Official Map in the Classroom: Memory Policies and Geography Classes in Ecuador (1875-1920)
}

\begin{abstract}
In this article we want to think about the invention of the official memory about the Ecuadorian territory during the $19^{\text {th }}$ and early $20^{\text {th }}$ century. We will address the teaching practices of national geography through a study of the content of geography books for children that were used in schools between 1875 and 1920. The article explores the ways in which geographic knowledge migrates from the country's official maps to texts that, initially, have a greater chance of being distributed. This dissemination element of geographic information is something that typically does not appear in papers on national maps and is indispensable viewpoint to link the study of geography with its impact on the creation of national identity.
\end{abstract}

The thesis that we want to state is that maps and the paradigms proposed by geographers, their images and their perspectives were well known and disseminated among educated individuals. In other words, they became part of public discourse and were useful for a more important group of people to be able to imagine the territory they shared with the other inhabitants and, thus, create the geographical fundamentals of a sense of nationality.

Keywords: Ecuador, Geography, Nationalism, Education.

\section{O mapa nacional na sala de aula: Políticas de memória e aulas de geografia no Ecuador (1875-1920)}

\begin{abstract}
Resumo
Neste artigo nosso interesse é pensar em como foi inventada a memória oficial sobre o território equatoriano durante o século XIX e começos do século XX. Trabalharemos as práticas de ensino da geografia nacional através de um estudo do conteúdo dos livros de geografia para crianças que foram usados nas escolas entre 1875 e 1920. O artigo explora as formas nas quais o conhecimento geográfico migra desde os mapas nacionais a textos que, em princípio, têm uma maior possibilidade de circulação. Este elemento de circulação da informação geográfica é algo que tipicamente não aparece nos trabalhos sobre mapas nacionais e é um ângulo indispensável para relacionar o estudo da geografia com seu impacto na construção da nação.

A tese que queremos expor é que os mapas e paradigmas propostos pelos geógrafos, suas imagens e suas perspectivas foram bem conhecidos e circularam dentro de um público educado. Em outras palavras, foram incluídos no discurso público e serviram para que um grupo mais importante da população fosse capaz de imaginar o território compartilhado com os demais habitantes e assim criar os fundamentos geográficos de um sentimento de nacionalidade.
\end{abstract}

Palavras chave: Ecuador, geografia, nacionalismo, educação. 


\section{Introducción}

"Es difícil, sin duda alguna, y muy difícil escribir la geografía de un país cuya mayor parte no se conoce"

Juan Bautista Menten fue un científico jesuita alemán que llegó al Ecuador en 1870 como parte de un ambicioso proyecto organizado por el gobierno para involucrar a la ciencia europea en la construcción del Estado-nación. Una decena de jóvenes jesuitas entrenados en distintas ramas de la ciencia llegaron junto con él para formar la planta docente de la flamante Escuela Politécnica Nacional. El gobierno buscaba diversificar la oferta académica del país, la cual se limitaba a la abogacía, la medicina y el clero, para formar ingenieros, geólogos y agrónomos, etc., que contribuyeran con la construcción del Estado-nación.

La cita con la que se introdujo este artículo es escrita por Menten al poco tiempo de su llegada. El científico alemán habla de la dificultad de escribir la geografía de un país cuya mayor parte es desconocida. En efecto, el territorio ecuatoriano en la segunda mitad del siglo XIX aun representaba una gran tierra incógnita. Únicamente, las provincias de la sierra-centro habían sido mapeadas y se conocía con algún grado de detalle los alrededores del puerto costero de Guayaquil. El resto del territorio (las grandes extensiones costeras y la enorme región amazónica) no se conocía más que el curso de los grandes ríos.

A pesar de este enorme desconocimiento del territorio desde el punto de vista científico, los niños recibían clases de geografía nacional en las escuelas. En este artículo se va a discutir sobre esta aparente contradicción. Interesa entender cómo se gestó la memoria oficial sobre el territorio ecuatoriano en el campo educativo. Se estudian las prácticas de enseñanza de la geografía nacional a través de un análisis del contenido de los libros de texto que se utilizaron en las escuelas. Estos textos fueron indispensables para la interiorización social de la representación oficial del espacio. Mediante el proceso educativo, la imagen oficial de la nación entra en la memoria colectiva para volverse, más tarde, memoria individual ${ }^{3}$. Todo esto permitió la formación de sujetos nacionales territorializados ${ }^{4}$.

Las geografías, que son las obras escritas por científicos como Menten, son textos demasiado largos y eruditos como para que se convirtieron en instrumentos de territorialización. Por otro lado, los mapas nacionales que acompañaron a estas geografías fueron muy grandes, caros y escasos como para ser distribuidos a todos los estudiantes del país. Estas dos fuentes de información científica son traducidas a imágenes mucho más reproducibles ${ }^{5}$ que sirvieron para que un grupo más importante

\footnotetext{
${ }^{2}$ Menten, J. "Escuela Politécnica”, El Nacional, 1871, p 12.

${ }^{3}$ Díaz Ángel, S. Contribuciones a la historia de la cartografia en Colombia: una red de investigadores y un caso de estudio.(Bogotá: Universidad Nacional de Colombia, 2008), p. 91.

${ }^{4}$ Sevilla, A. El Ecuador en sus mapas: Estado y nación desde una perspectiva espacial (Ecuador: FLACSO, 2013).

${ }^{5}$ Anderson, B. Comunidades imaginadas: Reflexiones sobre el origen y la difusión del nacionalismo (Mexico: Fondo de cultura, 1993).
} 
de la población lograra imaginar el territorio que compartían con el resto de habitantes y así construir las bases geográficas de un sentimiento de nacionalidad. Estas fuentes fueron traducidas en distintos niveles de complejidad que permitieron que su contenido se dispersara y ampliara; ese es el caso de los catecismos y clases de geografía para escuelas primarias. Bajo el apoyo del gobierno, la geografía entra en la enseñanza de las ciencias básicas para cumplir una función clave en la conformación del sentimiento nacional a través de la racionalización y homogenización del territorio.

Imagen 1. Villavicencio, M. (1858). Carta corográfica de la República del Ecuador. Nueva York, Lit. e Imp. de F. Mayer y C.

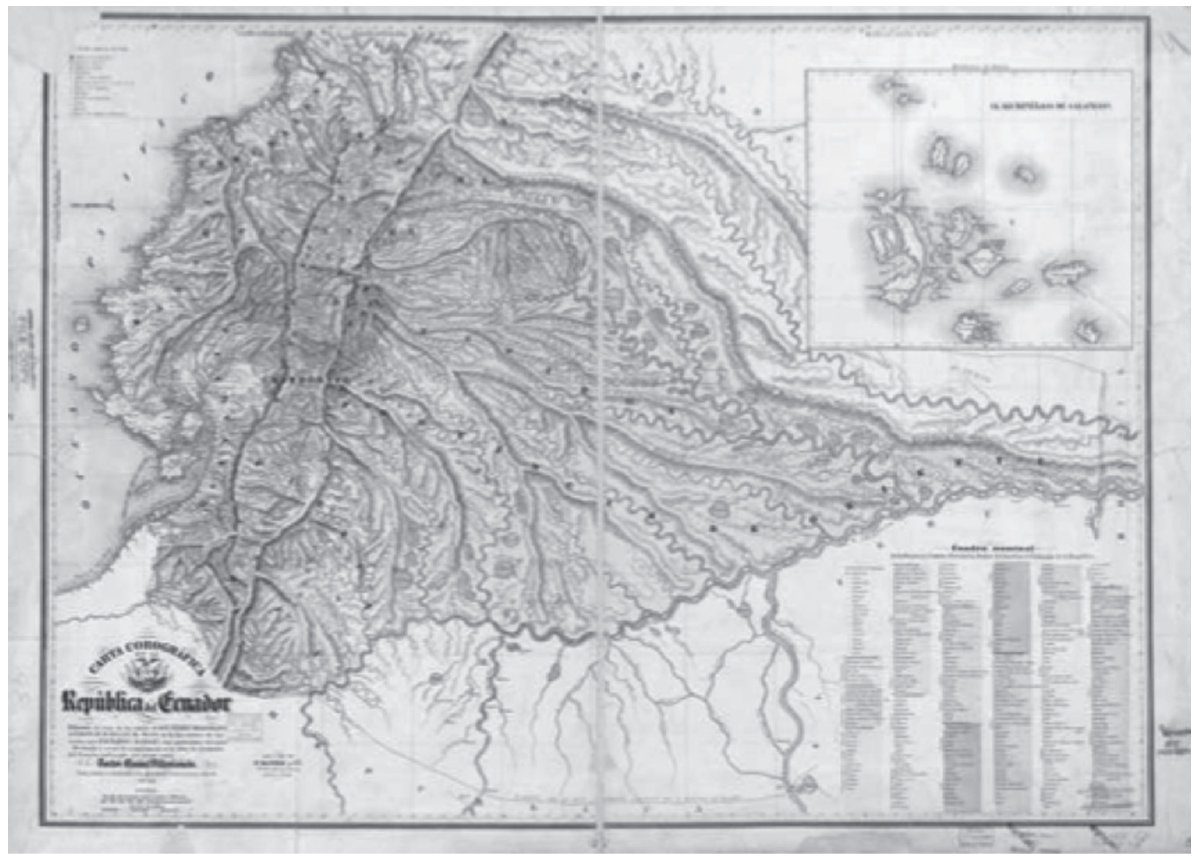

Fuente: Mapoteca Archivo Aurelio Espinosa Polit Quito.

\section{Mapas nacionales: conocimiento y poder}

¿Qué es la geografía sino el dibujo y la interpretación de una línea? ¿Y qué es el dibujo de una línea sino la creación de nuevos objetos? Qué líneas dibujamos, cómo las dibujamos y cuáles son los efectos provocados por estos dibujos, son preguntas cruciales ${ }^{6}$.

¿Qué se entiende como mapas nacionales? Según Anderson 7 , los mapas nacionales reflejan y regulan proyectos estatales y expresiones de la identidad nacional, al mismo tiempo que detallan información técnica sobre el territorio para la toma de decisiones.

${ }^{6}$ Pickles, J. A history of spaces: cartographic reason mapping and the geo-coded world (London: Routledge, 2004), p. 3.

${ }^{7}$ Anderson, B., Op. cit. 
A pesar de que representan el territorio entero de un Estado-nación, la escala y la cantidad de detalle que contienen refleja los significados culturales e imaginaciones socioespaciales de la cultura del Estado-nación más que una estructura detallada de información administrativa.

Esta definición es problemática para el caso que se propone estudiar, donde los tres elementos que son mencionados como determinantes en la estructura de un mapa nacional; el Estado, la nación y el territorio, no son necesariamente evidentes. De hecho, al igual que en Mexico ${ }^{8}$, Colombia ${ }^{9}$, Argentina $^{10}$ y en la mayoría de los territorios latinoamerican ${ }^{11}$, en el Ecuador del siglo XIX, el territorio es prácticamente desconocido, el Estado se encuentra fragmentado y disperso, y la nación es más una insinuación de las élites que un sentimiento de comunidad compartida. En este contexto, el poder del mapa recae en su capacidad de abstracción la cual ayuda a crear un efecto de Estado como aparato lógico mientras que esconde su precariedad ${ }^{12}$.

El elemento determinante en el análisis de los mapas tiene que ver con los efectos de poder que estos trasmiten. La geografía y el mapeo del territorio son importantes instrumentos del arte de gobierno ${ }^{13}$. Es por eso que cuando se observa un mapa nacional, inquietan siempre los motivos de su financiamiento y publicación; unos interrogantes que apuntan a la premisa de que la publicación de un mapa es por definición un acto político ${ }^{14}$ que se basa y que busca reforzar una determinada estructura de poder. Pero las respuestas a todas las preguntas que se plantean a los mapas no son siempre evidentes. De hecho, el mapa solo es capaz de entregar una imagen estable y sólida del espacio porque oculta discusiones de representación y hegemonía. Este doble movimiento característico del mapa, que lo hace bailar entre la revelación y el silencio ${ }^{15}$, es justamente el elemento que le entrega su enorme potencial como herramienta de dominación política.

\footnotetext{
${ }^{8}$ Craib, R. Cartographic Mexico: a history of state fixations and fugitive landscapes (London: Duke University Press, 2004).

${ }^{9}$ Appelbaum, N. "Reading the Past on the Mountainsides of Colombia: Mid-Nineteenth-Century Patriotic Geology, Archaeology, and Historiography”, en Hispanic American Historical Review, vol. XCIII, núm. 3, 2013, pp. 347-376.

Sánchez Cabra, E. “Agustín codazzi y el descubrimiento de San Agustín” Boletín de Historia y Antigüedades 857, vol. C, núm. 857, 2015.

${ }^{10}$ Lois, C. "Técnica, política y" deseo territorial" en la cartografía oficial de la Argentina (1852-1941)", en Scripta Nova: revista electrónica de geografía y ciencias sociales, vol. X, núm. 52, 2006.

${ }^{11}$ Dym, J. and Offen, K. Mapping Latin America: a cartographic reader. (USA: University of Chicago Press, 2011).

${ }^{12}$ Sparke, M. In the Space of Theory: Postfoundational Geographies of the Nation-State (USA: University of Minnesota Press, 2005), p. 10.

${ }^{13}$ Craib, R. Cartographic Mexico...

${ }^{14}$ Akerman, D. "The Structuring of Political Territory in Early Printed Atlases", en Imago Mundi, vol. XLVII, núms. 138-154, 1995, p. 139.

${ }^{15}$ Harley, J. B. La nueva naturaleza de los mapas: ensayos sobre la historia de la cartografia (Baltimore: He John Hopkins University Press, 2005).
} 
En este sentido, y de acuerdo a J. B. Harley ${ }^{16}$, el análisis de los mapas lleva a teorizar sobre la relación entre conocimiento y poder. Los mapas pueden ser vistos como elementos de poder que circulan para reforzar y legitimar una forma de ver el mundo. El mapa cumple un rol fundamental en la fijación de un escenario espacial y geopolítico sobre el cual se asienta el Estado-nación. En este sentido, la repetitividad e inflexibilidad de los mapas impresos es una acción que normaliza y de cierta manera, legítima un determinado punto de vista ${ }^{17}$. Este aspecto normativo de los mapas es de especial importancia para lo socialización del conocimiento geográfico con los niños. Existe una necesidad de distribuir e incluso imponer imágenes comunes, de tal forma que todos los niños que viven dentro de una sociedad compartan el mismo vocabulario espacial. De hecho, el poder del mapa en la definición y fijación de la imaginación geográfica de la juventud se complementa con la utilización de una serie de textos que traducen, en función de una audiencia específica, la compleja información levantada por los geógrafos. Esta migración de la información sobre el espacio hacia las clases de geografía permite leer la educación como un dispositivo hegemónico, en el sentido gramsciano de hegemonía cultural, que ayuda a fijar una visión determinada del mundo. Según este concepto, la educación se encargaría de una orientación geográfica específica dirigida a establecer la primacía de un concepto unitario de Estado, de nación y de territorio como algo conveniente y natural, e inhibiendo otras formas de concebir el espacio y su relación con un sistema de gobierno. En nombre de la nación, se genera en el pueblo, a través de la educación, una nueva cultura política que integra el país y permite conformar un bloque hegemónico que aglutina a gran parte de la población en torno a un mismo proyecto político ${ }^{18}$.

En este artículo se revisa los libros escolares de geografía publicados en el Ecuador entre 1875 y 1920 . Se ha tomado los textos escolares de este período de tiempo específico por algunas razones. En primer lugar, se considera que no existe una geografía escolar que se haya publicado antes de 1875, año en que publica Juan León Mera su catecismo. Por otro lado, el presente estudio se extiende hasta el año de 1920 para tratar de comprender la influencia a largo plazo que tuvieron los mapas nacionales de Teodoro Wolf ${ }^{19}$ y Enrique Vacas Galindo ${ }^{20}$. En este proceso de traducción y dispersión del conocimiento geográfico existe una marcada tendencia a reducir paulatinamente el grado de complejidad de la información entregada a los estudiantes. Esta reducción se manifiesta, por ejemplo, en el número de páginas que componen estas geografías escolares; comenzando con un libro de más de 130 páginas, en el caso de Juan León

\footnotetext{
${ }^{16}$ Ibid.

${ }^{17}$ Petchenik, B. "The natural history of the atlas: evolution and extinction", en Cartographica, vol. XXII, núm. 3, 1985.

${ }^{18}$ Cardona, P. "La nación de papel: Textos escolares, política y educación en el marco de la reforma educativa de 1870", en Co-herencia, vol. IV, núm. 6, 2007, pp. 87-113.

${ }^{19}$ Wolf, T. Carta Geografica del Ecuador por Dr. Teodoro Wolf, publicada por orden del Supremo Gobierno de la Republica y Trabajada Bajo las Presidencias de los EE. Senores Dr. D.J.M. Placido Caamano y Dr. D. Antonio Flores (Leipzig: Instituto geográfico de H. Wagner \& F. Debes, 1892).

${ }^{20}$ Vacas Galindo, E. Mapa geográfico-histórico de la República del Ecuador por el R. P. Fray Enrique Vacas Galindo de la Orden de los Predicadores (París: Henry Barrere, 1906).
} 
Mera; y terminando con un libro de menos de treinta páginas, en el caso de Felicísimo López.

\section{Ecuador: tierra incógnita}

Antes de entrar al análisis de los libros de texto, se discute brevemente sobre la historia de la cartografía en Ecuador. Teodoro Wolf, uno de los compañeros de Juan Bautista Menten y el autor del mapa nacional de 1892, define a los mapas del Ecuador como las "cartas geográficas que comprenden todo el territorio de la República y que han sido publicadas"21. De manera cronológica, se puede categorizar estos mapas en cuatro grupos. En primer lugar, se encuentran los mapas de la época colonial ${ }^{22}$; luego, los mapas del interludio grancolombino ${ }^{23}$; en tercer lugar, los mapas republicanos antes de la institucionalización de las ciencias geográficas -los que interesan en este estudio $^{24}$-; y en cuarto lugar, los mapas producidos a partir de 1928, año desde el cual el Instituto Geográfico Militar es la institución oficial para la producción de mapas del Ecuador ${ }^{25}$.

Los libros de texto que se analizan toman información de los mapas del periodo republicano. Específicamente, del médico quiteño Manuel Villavicencio ${ }^{26}$, del geólogo jesuita alemán Teodoro Wolf ${ }^{27}$ y del padre dominico nacido en Cotacachi, Enrique Vacas Galindo ${ }^{28}$. La publicación de cada uno de estos mapas está acompañada por un texto o Geografía que resume el estado de la cuestión del conocimiento geográfico. En estas Geografías se detallan los hitos geológicos, hidrográficos, demográficos e históricos del territorio y se discute también sobre las inestables y problemáticas relaciones con los países vecinos. A pesar de que los distintos geógrafos esperaban que el conocimiento geográfico fuera un proceso acumulativo (dado que la vida de un solo hombre no basta para recorrer y conocer el territorio en toda su extensión) y que cada Geografía debería ser una contribución al conjunto del conocimiento que se intentaba construir; cada nueva publicación tiene un enfoque sustancialmente distinto que pone en duda si existe una lógica o una institucionalidad en todo el proceso. Villavicencio, Wolf y Vacas Galindo presentan tres formas radicalmente diferentes de construir la cartografía del país y distintas maneras de articular este conocimiento con

\footnotetext{
${ }^{21}$ Wolf, T. Geografía y Geología del Ecuador por Teodoro Wolf (Quito: Editorial Casa de la Cultura, 1975 [1892]), p. 617.

${ }^{22}$ De los mapas coloniales, Wolf (1975) destaca tres (Fritz, 1707; La Condamine, 1745 y Maldonado, 1750).

${ }^{23}$ De los mapas del período grancolombino, Wolf (1975) destaca dos (Humboldt, 1825 y Restrepo, 1827).

${ }^{24}$ Después de la independencia (1830), Ecuador siguió sin carta propia hasta el año de 1858 en que salió a la luz la Carta corográfica de la República del Ecuador por Manuel Villavicencio. Luego, en 1892 se publicó la carta de Wolf.; y, finalmente, ya en el siglo XX se publica, en 1906, el mapa de Enrique Vacas Galindo.

${ }^{25}$ Tanto Capello (2010) como Radcliffe $(1996,2001,2009,2010,2011)$ han hecho valiosas contribuciones para el estudio de esta etapa.

${ }^{26}$ Villavicencio, M. Carta corográfica de la República del Ecuador (Nueva York: Lit. e Imp. de F. Mayer y C., 1858).

${ }^{27}$ Wolf, T. Carta Geografica del Ecuador...

${ }^{28}$ Vacas Galindo, E. Mapa geográfico-histórico de la República del Ecuador...
} 
la nación. Cada cartógrafo tiene sus propios objetivos, impulsos para hacer mapas, ideas sobre el rol de la ciencia y sobre la producción del conocimiento geográfico ${ }^{29}$.

El primer mapa del Ecuador republicano fue publicado en 1858; casi treinta años después de la Independencia del Ecuador de la Gran Colombia. Su autor, el médico quiteño Manuel Villavicencio, hizo el primer esfuerzo por presentar, de manera ordenada y sistemática, el conocimiento geográfico sobre la naciente República ${ }^{30}$. Su mapa, que está acompañado de un extenso texto de geografía ${ }^{31}$, se utilizó como instrumento de instrucción pública por más de treinta años. De igual manera, el trabajo de Villavicencio sirvió como fuente para los proyectos estéticos y pedagógicos de Juan León Mera. Es así que las bases geográficas de la novela Cumandá ${ }^{32}$, escrita en 1875, reflejan claramente la influencia del autor del primer mapa del Ecuador. Por un lado, los detalles de la hidrografía amazónica descrita por Villavicencio, particularmente la existencia del lago Chimano, son retomados por Mera como escenarios donde se desenvuelve la trama de la novela. De igual manera, los elementos etnográficos de Cumandá coinciden con la información que entrega Villavicencio sobre las tribus indígenas en la Amazonía ${ }^{33}$.

El contexto en el que Villavicencio publica su mapa era muy complejo; el estado de efervescencia social en el Ecuador era tal que el país estaba al borde de desaparecer. La soberanía del territorio ecuatoriano fue amenazada tanto por movilizaciones de poderes regionales, como por grupos subalternos e intentos de invasión tanto del Perú como de Colombia. La situación del Estado ecuatoriano era tan dramática, que no era posible imaginar mayores iniciativas en el ámbito de la integración material de la nación, sino que los avances debían iniciarse en el plano ideal ${ }^{34}$. A esto se sumaron las dificultades presentadas por la topografía andina y amazónica y las indefinidas y disputadas fronteras entre las nuevas repúblicas.

Dentro de este contexto de ruptura, Villavicencio construye un mapa que busca describir el Ecuador como una comunidad vinculada a un territorio. Su trabajo se basa en dos tipos de fuentes: por un lado, están las observaciones, mediciones y descripciones hechas en diversos viajes y en diversas épocas (ya sea los datos cartográficos recopilados por científicos y viajeros antes de Villavicencio o sus propias

\footnotetext{
${ }^{29}$ Sevilla, A. El Ecuador en sus mapas...

${ }^{30}$ Sevilla, A. Ciencia y nacionalismo en la construcción del primer mapa del Ecuador. Políticas de la Memoria y Descolonización en el Ecuador Bicentenario (1809-2009) (Ecuador, Quito: Proyecto Bicentenario FLACSO, 2010).

${ }^{31}$ Villavicencio, M. Geografia de la República del Ecuador (Quito: Corporación Editora Nacional, 1984 [1858]).

${ }^{32}$ Mera, J. L. Cumandá (Ecuador: Libresa, 1985 [1879]).

${ }^{33}$ Padron, R. "Cumandá and the cartographers: nationalism and form in Juan León Mera”, en Annals of Scholarship, vol. XII, núms. 3-4, 1998, pp. 217-234.

${ }^{34}$ Maiguashca, J. "El proceso de integración nacional en el Ecuador: el rol del poder central 1830-1895", en Maiguashca, J., Historia y región en el Ecuador: 1830-1930 (Ecuador: Proyecto FLACSO-CERLAC IV Corporación Editora Nacional, 1994), pp. 355-420.
} 
observaciones en el Oriente) las cuales denotan un conocimiento de primera mano del terreno pero que por definición es escaso e incompleto; y por otro lado, están las leyendas e imaginaciones de todo lo que no se conoce, lo cual supone una información mucho menos precisa y mucho más difusa, pero que va construyendo un cuerpo de conocimiento desde donde se puede concebir lo que no es posible conocer. Estas dos fuentes de información se mezclan a lo largo del trabajo de Villavicencio; de ahí que su trabajo haya sido catalogado por Teodoro Wolf como un error fantástico. En la idea del error se puede notar el diálogo entre estos dos sistemas de conocimiento, ya que este concepto hace referencia al primer tipo de fuente, en el que la medida y la observación pueden ser cuantificadas; mientras que la definición de fantasía lleva al segundo tipo de conocimiento, donde la imaginación es la que prima.

Imagen 2: Wolf, T. Carta Geográfica del Ecuador, por Dr. Teodoro Wolf, publicada por orden del Supremo Gobierno de la Republica y trabajada bajo las Presidencias de los EE. UU., señores Dr. D.J.M. Placido Caamano y Dr. D. Antonio Flores. Leipzig, Instituto geográfico de H. Wagner \& F. Debes, 1892.

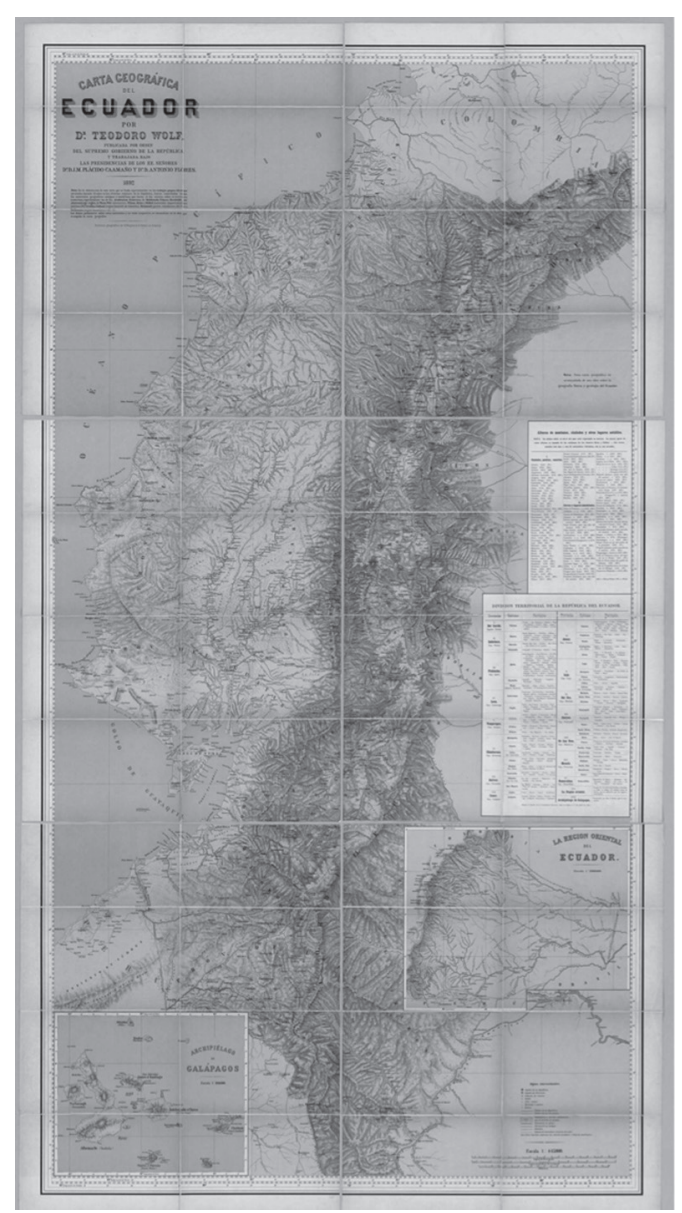

Fuente: Mapoteca Archivo Aurelio Espinosa Polit Quito. 
En 1892 el mapa de Villavicencio fue reemplazado por el mapa de Teodoro Wolf, el cual revolucionó la concepción de la geografía en el Ecuador y opacó el aporte de Villavicencio. A lo largo de sus escritos, Wolf descalifica sistemáticamente el mapa de Villavicencio, argumentando que sus ilusiones patrióticas parecen ser más fuertes que su rigurosidad científica. La fuerte crítica de Wolf junto con la autoridad científica que adquirió su mapa han relegado al olvido la propuesta geográfica de Villavicencio, considerándola un trabajo acientífico, caduco y lleno de falacias que no se debe repetir y mucho menos enseñar.

Por ejemplo, una de las críticas tiene que ver con su técnica de representación de los ríos del Oriente. Salta a la vista en el mapa de Villavicencio la trayectoria de los ríos del Oriente dibujada con unas serpentinas perfectamente simétricas. Elemento que es evidente en la siguiente sección de su mapa:

Imagen 3. Detalle de la técnica para dibujar ríos en el mapa de Manuel Villavicencio (1858).

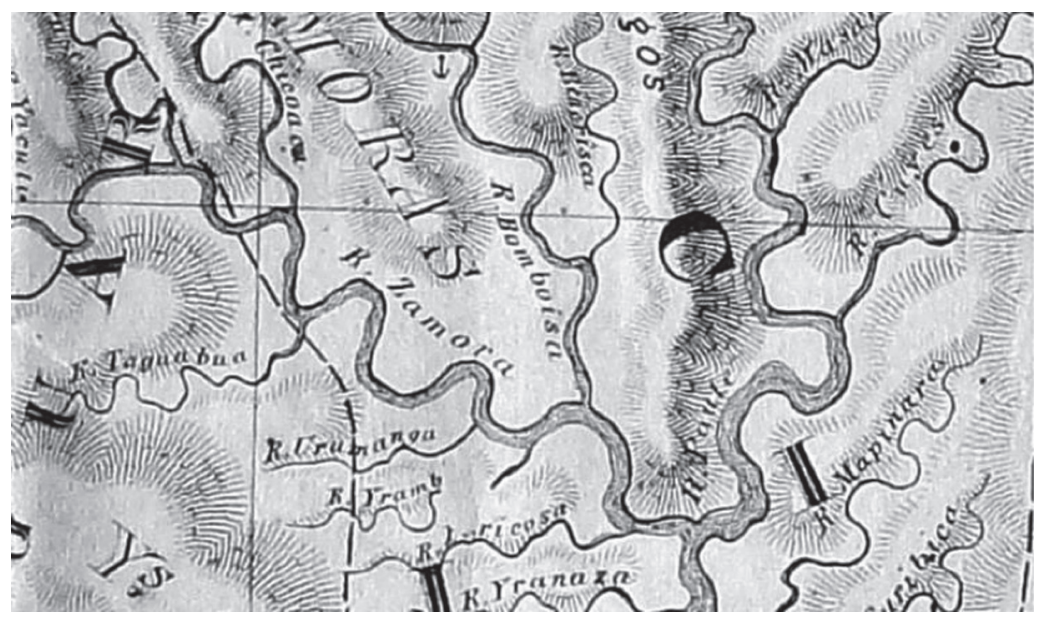

Fuente: Mapoteca Archivo Aurelio Espinosa Polit Quito.

Wolf critica fuertemente esta metodología de representación del espacio:

Puede ser que exista la mayor parte de los ríos y riachuelos, que nos indica, pero ciertamente no así como los pintó en el mapa. Con su desgraciada manía de convertir todos los ríos en tirabuzones, casi del mismo largo y grueso, no solo afecta su carta, sino que la hace confusa e imposible ${ }^{35}$.

\footnotetext{
${ }^{35}$ Wolf, T. Geografía y Geología del Ecuador por Teodoro Wolf (Quito: Editorial Casa de la Cultura, 1975 [1892]), p. 242.
} 
Teodoro Wolf fue uno de los jesuitas alemanes traídos por el presidente García Moreno para formar parte de la Escuela Politécnica ${ }^{36}$. Vivió por más de veinte años en el Ecuador, entre 1870 y 1891, y seguramente conoció este territorio con mucha más profundidad que cualquier otro personaje de su época. Esta larga permanencia en un país que a su juicio estaba lleno de poetas y no de hombres de ciencia, frustró a cada paso al metódico científico quien no encontraba interlocutores que compartieran su afición por el razonamiento lógico y la exactitud matemática. Pero este contexto dominado por la fantasía también lo volvió más sensible y creativo. Su texto de geografía y su mapa del Ecuador, publicados en 1892 como obras cúspide de todo su trabajo científico en el país, son muestra de esta tensión entre la erudición y la poesía. La siguiente cita de Wolf muestra esa alma lúdica del científico que encuentra momentos de belleza mientras descifra las leyes del universo:

Una determinada distribución geográfica se manifiesta en todos los órdenes de insectos, pero en ninguno es más fácil de observar que en el de los Lepidópteros diurnos (Mariposas). De más de 500 especies, que poco a poco recogí en mis viajes (sin contar las nocturnas y crepuscularias), unas dos docenas me servían como de barómetro, y me divertía adivinando de su aparición las alturas aproximativas en que me hallaba ${ }^{37}$.

En 1906, 14 años después de la publicación del mapa de Teodoro Wolf y dentro del contexto de una de las varias crisis militares por problemas fronterizos con el Perú, el gobierno ecuatoriano, por tercera ocasión, toma la decisión de reemplazar el mapa oficial del país. De hecho, a pesar de su reconocido rigor científico, el mapa de Teodoro Wolf no servía como instrumento de representación dentro de la complicada atmósfera retórica de un nuevo amenazante conflicto armado ${ }^{38}$. A pesar de haber sido creado con la intención de servir como instrumento público, el mapa de Wolf no se manifestaba en relación con la propiedad nacional. El énfasis de Wolf se centró en la construcción topográfica e hidrográfica del territorio, pero no hizo mayores esfuerzos por consolidar la dimensión nacional a través de la cartografía. De hecho, el territorio oriental que se disputaba entre los dos países no aparecía dentro del mapa de Wolf como una parte continua del territorio nacional ${ }^{39}$. Wolf dibuja el Oriente dentro de un

\footnotetext{
${ }^{36}$ Sobre la vida de Wolf: Cuvi, N., A. Sevilla, et al. "Entre Darwin y Dios: las primeras clases universitarias sobre el origen de las especies dictadas en el Ecuador (1871)", en Puig-Samper F. O., Miguel Ángel; Ruiz, Rosaura y Uribe, J. Alfredo, «YAMMERSCHUNER». Darwin y la darwinización en Europa y América Latina (Madrid: Ediciones Doce Calles, 2015).

${ }^{37}$ Ibid., p. 510.

${ }^{38}$ Padron, R. "Cumandá and the cartographers: nationalism and form in Juan León Mera", en Annals of Scholarship...Op. cit., p. 217.

${ }^{39}$ Sevilla Perez, A. "La incompleta nacionalización de la amazonía ecuatoriana en el siglo XIX vista desde el mapa de Theodor Wolf (1892)", en Apuntes. Revista de estudios sobre patrimonio cultural, vol. XXVI, núm. 1, 2013.
} 
inserto en uno de los márgenes del mapa, solamente marca a grandes rasgos el curso de los principales ríos y coloca una leyenda que dice "zonas poco conocidas habitadas por indios salvajes" ${ }^{40}$.

Imagen 4. Detalle de la leyenda en el recuadro de la región oriental del mapa, de Teodoro Wolf: Regiones poco conocidas habitadas por indios salvajes, 1892.

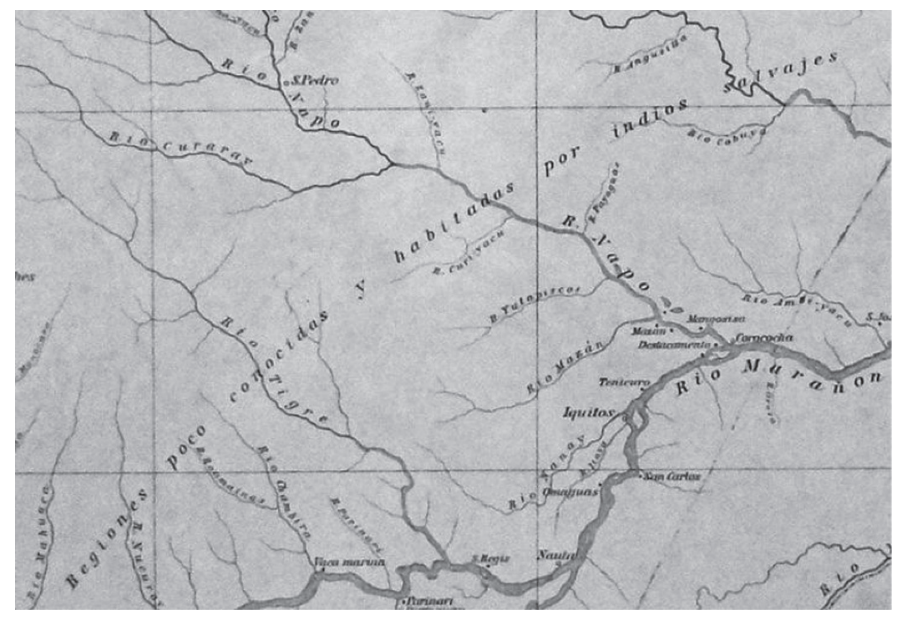

Fuente: Mapoteca Archivo Aurelio Espinosa Polit Quito.

Dentro de un contexto bélico, este mapa podría ser comprendido, tanto en ojos domésticos como internacionales, como una traición a una de las funciones ideológicas principales de la cartografía nacional: la de naturalizar una imagen del Estado como una entidad territorial coherente con fronteras no permeables.

El mapa que remplazó el de Teodoro Wolf fue producido por el Fraile dominico Enrique Vacas Galindo (1865-1938). En esta nueva representación cartográfica, se incluye no solo el territorio que fue marginalizado por Wolf, sino una gran sección que en ese entonces estaba bajo control peruano. A diferencia de sus antecesores, Vacas Galindo entrega con profundidad histórica y política al territorio y lo deja de ver como una red de montañas, ríos, quebradas y valles, para concebirlo como un terreno en disputa. Dentro de este contexto, su contribución al problema del territorio nacional se centra en su investigación de archivo y en la gran cantidad de documentos históricos que aporta a la discusión. Esta información es constantemente contrastada y debatida a la luz de los debates fronterizos de la época. Vacas Galindo cuestiona la premisa de que el Ecuador no dispone de la documentación suficiente para justificar sus derechos sobre los territorios disputados por el Perú en la región Oriental. Esta creencia, por demás errónea -en la opinión de Vacas Galindo- es debida a la poca atención que han prestado los Gobiernos del Ecuador al estudio de la cuestión de límites; elemento que es evidente en el trabajo de Teodoro Wolf.

\footnotetext{
${ }^{40}$ Wolf, T. Carta Geografica del Ecuador...
} 
El análisis de estos textos geográficos, que son la materia prima con la cual se construyen los mapas, pone en evidencia las tres transformaciones que caracterizan al conocimiento cartográfico y que son el origen de la utilidad que los nacionalismos nacientes encuentran en los mapas ${ }^{41}$. En primer lugar, está la geografía tal cual se presenta al cartógrafo. En segundo lugar, las técnicas científicas de mapeo del territorio abstraen el territorio de tal manera que la cartografía ya no solo muestra lo que está ahí, sino que se anticipa a la realidad espacial y se convierte en un modelo para lo que se quiere representar. El conocimiento científico se transforma entonces en un objeto de proyección. Esta característica de anticipación está muy presente en las Geografías del siglo XIX especialmente en el manejo de todo lo que en la época es considerado como tierra incógnita.

A partir de este punto donde el mapa es un objeto de proyección, hay una tercera transformación en la cual el conocimiento de los cartógrafos migra hacia otras esferas como el aula de clase. El conocimiento del espacio se desprenda de sus referencias geográficas predominantes y se convierta en signo, en logotipo. Interesa analizar cómo el conocimiento de la geografía salta de un dominio a otro y a su paso crea sujetos territorializados. Este cambio le entrega una dimensión nueva a la cartografía: la posibilidad ilimitada de reproducción, la cual se basa en una permanente migración del conocimiento geográfico; del terreno al libro de geografía, del libro a la imagen del mapa, y finalmente de la imagen a la educación. Estos espacios hacia donde migra el conocimiento geográfico ponen en evidencia la manera en que otros actores interpretan y transforman esta información, fortaleciendo ciertos mitos y creando algunos nuevos. De esta forma, al analizar la educación y el mapa como eventos de territorialización surgen las preguntas sobre cómo circula el conocimiento geográfico enunciado en primera instancia por los geógrafos y más tarde utilizado por públicos diversos para construir poco a poco una imagen del territorio. Esta ampliación del circuito, fruto de la migración de las ideas geográficas, es la base de la relación del territorio con el Estado- nación.

\section{Juan León Mera y el primer catecismo sobre geografía}

Al igual que la mayoría de escritores en Sudamérica del siglo XIX, Mera fue también una figura política ${ }^{42}$. A pesar de que comenzó su carrera como liberal, se juntó a la línea conservadora cuando Gabriel García Moreno llegó al poder en 1860, fue parte de la Asamblea Constituyente y gobernador de la provincia de Tungurahua ${ }^{43}$. Mera se interesó mucho por el proyecto educativo de García Moreno, fundó varias escuelas en Tungurahua y escribió el Catecismo de geografía que fue adoptado para el uso en los colegios en 1875. Su catecismo reduce la nación, su geografía, su historia, su

\footnotetext{
${ }^{41}$ Anderson, B. Comunidades imaginadas...

${ }^{42}$ Vallejo, R. 1., Mera, Juan León y Araujo, D. Historia de las literaturas del Ecuador, Literatura de la República 1830-1895. (Ecuador: Corporación Editora Nacional y Universidad Andina Simón Bolívar, vol. III, 2002, p. 212.

${ }^{43}$ Ayala Mora, E. (ed.), Nueva Historia del Ecuador (Quito: Corporación Editora Nacional/Editorial Grijalbo Ecuatoriana, 1990).
} 
demografía y su sistema de gobierno a una edición de bolsillo de 131 páginas. A través de este libro, los niños aprenderían a imaginar la nación y a encontrar su lugar dentro de este espacio, dentro de su historia y dentro de sus estructuras de autoridad ${ }^{44}$.

El catecismo de Mera lleva como subtítulo: "Para el uso de las escuelas de esta República”. En la época en que publica Juan León Mera existen 435 escuelas en el Ecuador; 367 de niños y 63 de niñas. Cerca de 22.500 niños concurren a las escuelas y una cuarta parte son del sexo femenino ${ }^{45}$. En la advertencia, el autor resalta que "la falta de un texto para la enseñanza de la geografía patria" ${ }^{46}$ es una necesidad latente de todos los establecimientos de instrucción, públicos o privados. Es bajo "el convencimiento de esta necesidad" 47 y el deseo que le "han mostrado algunos maestros" ${ }^{\text {48 }}$ de que él la llenase, así como de su propio anhelo de coadyuvar por este lado al adelanto de las escuelas con el que Mera justifica la publicación de su obra.

La estructura del texto del catecismo de Mera se da bajo la forma de un diálogo donde la voz P enuncia una pregunta, seguida de una réplica de la voz R con una respuesta ${ }^{49}$. La primera pregunta es “¿Qué cosa es la República del Ecuador?" ${ }^{50}$, seguida de la respuesta: "Es una Nación libre independiente de la América del Sur"51 Luego, “Por qué lleva el nombre de Ecuador?"52, y responde "Porque está situada bajo la línea equinoccial" 53 . El texto inicia con una sección de Geografía física, seguida de una segunda parte sobre la Geografía política y civil. Por último una tercera parte titulada "Geografía descriptiva e histórica". El tono del texto es conciso y da la impresión de absoluta objetividad en los datos. Las preguntas son directas y las respuestas son cortas. Este estilo cambia radicalmente en dos momentos que delatan tanto los gustos y las pasiones del autor por aspectos específicos de la geografía del país, como su tendencia poética en la escritura que está censurada en el resto del texto. Los Andes y el Oriente son los espacios que despiertan esta veta poética de Mera que parece olvidar que está escribiendo un catecismo para niños de colegio. En ambos casos, las respuestas son largas y descriptivas. Mera recurre al ojo del viajero y explorador como punto de vista para la descripción tanto de los Andes como de las selvas orientales, lo cual pone énfasis en lo remoto y desconocido de estos parajes.

\footnotetext{
${ }^{44}$ Padron, R. "Cumandá and the cartographers: nationalism and form in Juan León Mera", en Annals of Scholarship...Op. cit., p. 221.

${ }^{45}$ Mera, Juan León. Catecismo de geografía de la República del Ecuador, Quito: Imprenta Nacional p.67.

46 Ibid., part. 2.

${ }^{47}$ Ibid.

48 Ibid.

${ }^{49}$ En la segunda edición del texto (1884), Mera cambia las voces, ya no son P, de pregunta y R, de respuesta, sino $\mathrm{M}$, de maestro y $\mathrm{D}$, de discípulo.

${ }^{50}$ Ibid., p. 1.

${ }^{51}$ Ibid.

${ }^{5}$ Ibid.

${ }^{53}$ Ibid.
} 
De hecho, en la segunda edición del catecismo, al final de la descripción sobre las selvas del Oriente, Mera ${ }^{54}$ incluye un comentario del maestro que dice: "Bien, querido discípulo, ha descrito usted como un poeta". En relación con la zona oriental, esta primera descripción de sus bosques y misterios, de la "magnificencia y riqueza de sus selvas y ríos" ${ }^{55}$ contrasta con los comentarios finales del autor de que la provincia de Oriente, a pesar de ser “[...] la más extensa y privilegiada provincia del Ecuador [...] no tiene otra cosa notable que sus recuerdos y esperanzas" ${ }^{\prime \prime}$.

Al igual que la opinión del jesuita Juan Bautista Menten, el primer elemento que resalta Mera sobre el conocimiento de la geografía del Ecuador es que es una tarea incompleta e imperfecta. En este sentido, el autor declara en las primeras líneas que su trabajo no es más que "[...] la recopilación epitomada de lo poco que hasta hoy han podido hacer algunos hombres científicos y estudiosos, de los datos que [ha] sacado de muchos documentos públicos y particulares que [ha] tenido a la vista, y de tal cual observación propia”. Hecha esta aclaración, Mera considera innecesario el detenerse en citar las fuentes que ha utilizado para escribir este 'librito' ${ }^{57}$. A pesar de esta aclaración, Se puede encontrar una clara evidencia de la influencia del trabajo del geógrafo quiteño Manuel Villavicencio en la obra de Mera.

En 1858 salió a la luz la Carta corográfica de la República del Ecuador, por Villavicencio. Esta carta acompañó la Geografía de Manuel Villavicencio que es el primer esfuerzo por presentar, de manera ordenada y sistemática, el conocimiento geográfico sobre la República del Ecuador ${ }^{58}$. Villavicencio justifica su trabajo en función de la vergüenza que siente de que "[...] un pueblo tan rico i tan hermoso se viera ignorado de tal modo por las naciones más civilizadas"; el autor se propone dar a conocer al Ecuador al mundo por medio de una Geografía ${ }^{59}$. En los textos de geografía que se publican después del trabajo de Villavicencio, como el Catecismo de Geografía, de Juan León Mera ${ }^{60}$ y la Geografía del Ecuador de los Hermanos Cristianos $^{61}$, se siguió repitiendo lo escrito por Villavicencio, detalle que revela la difusión y el prestigio que alcanzó su libro ${ }^{62}$.

Al referirse al mapa de Villavicencio, Wolf menciona que es bien conocido en el país, pero que ha sido censurado en varias ocasiones por nacionales y extranjeros. Una

\footnotetext{
${ }^{54}$ Ibid., p. 22.

${ }^{55}$ Ibid., p. 141-142.

${ }^{56}$ Ibid.

${ }^{57}$ Ibid., part. II.

${ }^{58}$ Sevilla, A. El Ecuador en sus mapas...

${ }^{59}$ Villavicencio, M. Geografía de la República del Ecuador (Quito: Corporación Editora Nacional, part. VII, 1984 [1858].

${ }^{60}$ Mera, Juan León. Catecismo de geografía..

${ }^{61}$ Hermanos de las Escuelas Cristianas. Geografia de la República del Ecuador arreglada por los Hermanos de las Escuelas Cristianas para el uso de sus alumnos (Guayaquil: Imprenta de Calvo, 1881).

${ }^{62}$ Terán, F. "La geografía del Ecuador del Dr. Manuel Villavicencio”, en Villavicencio, M., Geografía de la República del Ecuador (Quito: Corporación editora nacional, vol. XI-XXVII, 1984).
} 
de las sanciones más fuertes es la pronunciada por el científico inglés Richard Spruce, quien utilizó el mapa pocos años después de su publicación. En 1861, en el reporte sobre su expedición para recoger semillas y plantas de Cinchona, Spruce señala que:

Recientemente se ha publicado un trabajo topográfico sobre el Ecuador [...], que dado que ha sido impreso en buen papel y está acompañado por un mapa de gran escala finamente grabado, probablemente va a ser recibido en Europa con un grado de crédito que no se merece ${ }^{63}$.

"El trabajo -continúa Spruce- ya ha sido criticado severamente, y sus errores más evidentes han sido destacados, por la prensa de Quito" ${ }^{64}$, pero considera que es muy difícil que estas críticas y correcciones lleguen a los geógrafos europeos, por lo cual decide incluir su protesta en este reporte ${ }^{65}$. En su Geografía, Wolf transcribe la sección más dura de la crítica de Spruce:

\begin{abstract}
Parece que el autor -señala Spruce a propósito de la obra de Villavicencio-no tiene idea clara entre Norte y Sur, Este y Oeste, puesto que emplea muchas veces uno de estos términos en lugar del opuesto. En el mapa muestra el autor su ignorancia de los primeros principios de geografía por la numeración errónea de los minutos de longitud y latitud; y los nombres están muchas veces tan equivocados en sus posiciones, como si los hubiera escrito sobre pedazos de papel y recibido sobre el mapa después de lanzarlos al aire, fijando así su posición respectiva ${ }^{66}$.
\end{abstract}

Juan León Mera entabló una importante relación con Richard Spruce. De hecho, las experiencias de Spruce en el Oriente ecuatoriano (en busca de la cascarilla) son una de las fuentes de inspiración para que Mera escriba su obra literaria más conocida: Cumandá. La anécdota central de la obra le pertenece a Richard Spruce quien comparte la leyenda con Mera. En carta al director de la Real Academia Española el 10 de marzo de 1877, Mera cuenta que "Cumandá es el nombre de una heroína de aquellas desiertas regiones (las vírgenes selvas del Oriente de la República), muchas veces repetido por un ilustrado viajero inglés, amigo mío, cuando me refería una tierna anécdota, de la cual fue, en parte, ocular testigo, y cuyos incidentes entran en la urdimbre del presente relato"67. La relación entre Mera y Spruce podría explicar la omisión de Mera de su lectura de Villavicencio.

\footnotetext{
${ }^{63}$ Spruce, R. Report of the expedition to procure seeds and plants of the Cinchona Succirubra or Red Bark Tree (London: George E. Eyre and William Spottiswoode, 1861), p. 5.

${ }^{64}$ Ibid.

${ }^{65}$ Ibid.

${ }^{66}$ Spruce, R. Report of the expedition ..., citado en Wolf, T. Geografia y Geología del Ecuador..., p. 621.

${ }^{67}$ Mera, J. L. Cumandá..., p. 33.
} 


\section{Los Hermanos Cristianos}

Los Hermanos de las escuelas cristianas llegaron al Ecuador en 1863 bajo el auspicio del presidente Gabriel García Moreno (1821-1875) para encargarse de varias escuelas de niños. Su llegada forma parte de una serie de reformas que buscan desarrollar instituciones modernas en el Ecuador. El gobierno ecuatoriano importa modelos europeos con la ayuda de diferentes comunidades religiosas que manejaron los hospitales, las cárceles y las escuelas.

En 1881, seis años más tarde de la publicación del catecismo de Mera, los Hermanos de las escuelas cristianas publican una Geografía de la República del Ecuador para el uso de sus alumnos. Este trabajo se basa fundamentalmente en el catecismo de Mera del cual se toman "párrafos enteros con poquísimas alteraciones o abreviaciones". Al igual que en el caso de Mera, las fuentes geográficas de la obra no se especifican (se repite la utilización de Villavicencio y la omisión de su nombre), lo único que se especifica es que "para componer estas lecciones de Geografía del Ecuador" se utilizan "las varias obras que tratan de este importante ramo de instrucción nacional". Una diferencia en el uso de fuentes entre Mera y los Hermanos Cristianos, que se mantendrá en trabajos posteriores, es que se cita la información de la Constitución y la Ley de División Territorial. El libro es aún más pequeño que el de Mera (78 páginas) e incluye, al final, un cuadro alfabético de las provincias, capitales, cantones y parroquias, y un "Cuestionario o numerosos ejercicios propios para dar a los alumnos la inteligencia de las lecciones, familiarizarles con ellas y dejarles bastantes conocimientos de Geografía patria" ${ }^{68}$. En varios lugares del texto, se encuentran instrucciones específicas para el profesor que vinculan la geografía con el mapa ${ }^{69}$ como por ejemplo: "el profesor puede mostrar a los alumnos los demás cabos y puntas en el mapa"70. De igual manera, en el cuestionario hay una indicación que dice: “[...] estos ejercicios puede el profesor variarlos a voluntad: multiplicarlos, cambiarlos, subdividirlos; formular la misma pregunta de varios modos"71.

A partir de $1885^{72}$, la iniciativa de educación geográfica de los Hermanos de las escuelas cristianas se vuelve más ambiciosa con la publicación de un texto titulado Geografia infantil, nociones de Geografía física y politica por los Hermanos Cristianos para el uso de sus alumnos ${ }^{73}$. De hecho, la Geografía infantil es un curso de Geografía elemental dividido en varios cuadernos: un cuaderno sobre nociones de la Geografía física y política, un cuaderno sobre la Geografía del Ecuador, un cuaderno sobre nociones de Geografía universal y general de América, un cuaderno sobre

\footnotetext{
${ }^{68}$ Hermanos de las escuelas cristianas. Geografía de la República del Ecuador... , part. V.

${ }^{69}$ El libro hace referencia a la carta de los alumnos de las HH., de las escuelas cristianas de Guayaquil. Este mapa fue encontrado en la mapoteca Aurelio Espinosa Pólit.

${ }^{70}$ Hermanos de las escuelas cristianas. Geografía de la República del Ecuador..., p. 7.

${ }^{71}$ Ibid.

${ }^{72}$ Esta es la segunda edición del texto. No se ha tenido acceso a la primera edición.

${ }^{73}$ Hermanos de las escuelas cristianas. Geografia Infantil, Nociones de Geografía física y política por los Hermanos Cristianos para el uso de sus alumnos, 2da edición (Guayaquil: Imprenta de la Nación, 1885).
} 
Geografía general de Europa, Asía, África y Oceanía, y un cuaderno sobre nociones de Cosmogonía. La publicación se justifica en función de una serie de criterios. Entre ellos, la "necesidad de dar a los niños una enseñanza metódica y gradual"", la importancia de los ejemplos locales y el costo de los libros para los niños. De esta forma, la Geografía del Ecuador se enseña en las escuelas de los Hermanos Cristianos como un capítulo dentro de un curso general de Geografía.

\section{Roberto Andrade}

Entre 1899 y 1920 el liberal Roberto Andrade publica 14 ediciones de un texto escolar elaborado bajo el título Lecciones de geografía de la República del Ecuador para los niños. La segunda edición ${ }^{75}$ empieza con una sección sobre Documentos oficiales que le entregan el carácter oficial a la iniciativa de Andrade. Primero, se presenta una carta dirigida al señor presidente del Consejo de Instrucción Pública y firmada por Celiano Monge, director de Estudios de la Provincia de Pichincha que dice que "[...] el señor Roberto Andrade es uno de los pocos escritores nacionales que se han dedicado a componer textos de enseñanza primaria"76 y donde se considera que su obra es funcional para las escuelas. Monge advierte el estilo claro y sencillo de los textos, característica propia del ejercicio destinado a la instrucción de la niñez. De igual forma, Monge resalta, como en el caso de los Hermanos Cristianos, “[...] la aplicación de las enseñanzas a la Ley de División Territorial expedida por la última Constituyente" "77. Estas dos razones llevan a Monge a sugerir que se declare como texto la publicación de Andrade $^{78}$. La carta de Monge es seguida de una contestación, firmada por Luis N. Dillon donde se declara que "[...] el Consejo General de Instrucción Pública, vista la solicitud del señor Roberto Andrade, y previo informe del señor Director de Estudios de la Provincia de Pichincha" 79 , acuerda declarar texto para las Escuelas del Estado la obra Lecciones de Geografía de la República del Ecuador.

Las Lecciones de Geografía de Andrade son libros pequeños de alrededor de setenta páginas que no incluyen mapas. La obra está dividida en tres secciones, siguiendo el modelo de Mera. La primera parte describe la geografía física; la segunda, describe la geografía política y civil; y la tercera parte, corresponde a la geografía descriptiva. Cada sección está dividida en diferentes lecciones, y al final de cada lección hay una serie de preguntas para los estudiantes. Por ejemplo, la serie de preguntas al final de la lección 2 es la siguiente: “¿En cuántas regiones está divido naturalmente el Ecuador y qué lo divide? ¿Cómo es la Región litoral? ¿Cómo la central? ¿Cómo la Oriental?’"80.

\footnotetext{
${ }^{74}$ Ibid.

75 Andrade, Roberto. Lecciones de Geografia para los niños, 2da edición (Guayaquil: Imprenta del Universo, 1899). Solo se pudo analizar el trabajo de Andrade desde la segunda edición. La primera edición no está disponible en el archivo consultado (Aurelio Espinosa Pólit).

${ }^{76}$ Ibíd.

${ }^{77}$ Ibid.

${ }^{78}$ Andrade, Roberto. Lecciones de Geografia ..., parts. I-II.

${ }^{79}$ Ibid., p. III.

${ }^{80}$ Ibid., p. VIII.
} 
Las nuevas publicaciones que aparecen cada año no incluyen modificaciones importantes en el contenido. Las primeras siete ediciones (entre 1899 y 1910) incluyen una nota al final que dice que "[...] el estudio de esta geografía debe hacerse con vista del mapa del doctor Wolf, el más perfecto de todos los que existen"\$1. En 1910, en la octava edición de las Lecciones, Andrade ya no toma a Wolf como la mejor referencia sino que cita a Felicísimo López: “[...] el estudio de esta Geografía debe hacerse con vista al atlas del Dr. Dn. Felicísimo López, Cónsul General del Ecuador en New York, que es el trabajo más perfecto de todo los que existen sobre la materia" ${ }^{22}$. El atlas de Felicísimo López es arreglado según la carta de Wolf. Esta referencia se mantiene hasta la edición de 1920. En ningún momento se menciona al mapa de Enrique Vacas Galindo como referencia.

Imagen 5: Vacas Galindo, E. Mapa geográfico-histórico de la República del Ecuador, por el R. P. Fray Enrique Vacas Galindo de la Orden de los Predicadores. París, Henry Barrere, 1906.

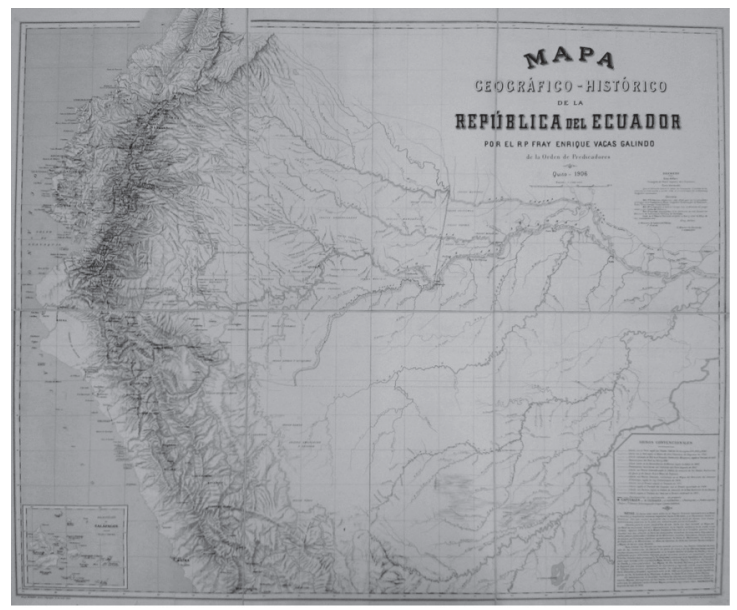

Fuente: Mapoteca Archivo Aurelio Espinosa Pólit.

La influencia de Wolf en el trabajo de Andrade se nota en la cantidad de información que entrega de cada una de las zonas del país. De hecho, Andrade utiliza cinco lecciones para describir la región litoral; tres, para la región interandina, y solamente una muy corta para la región oriental donde solo se da información de los grandes ríos, se menciona que el sistema orográfico (o sea las cordilleras) no ha sido estudiado y que tampoco se puede determinar ni la extensión del territorio ni sus límites. El Oriente se describe como un territorio "[...] feracísimo, cubierto de selvas seculares, cruzado por inmensos ríos y por varias cadenas de montes, no todas conocidas hasta ahora" ${ }^{83}$. Se encuentra una clara diferencia con el enfoque poético de Mera en la

\footnotetext{
${ }^{81}$ Ibid., p. 69.

${ }^{82}$ Ibid.

${ }^{83}$ Ibid., p. 68.
} 
descripción del Oriente, que es luego retomado al pie de la letra por los Hermanos Cristianos, y que parece ser una clara influencia del trabajo de Villavicencio.

\section{Felicísimo López}

En 1907 el médico liberal Felicísimo López publica su Atlas Geográfico del Ecuador, arreglado según la carta del Dr. Teodoro Wolf ${ }^{84}$. López fue alumno de Teodoro Wolf en la Escuela Politécnica de Quito. A diferencia del catecismo de Mera en donde no se especifica directamente las fuentes de las que se toma la información geográfica, y del trabajo de Andrade donde la referencia se encuentra en una nota en la última página del texto, el trabajo de Felicísimo López se vincula, desde el título, directamente con la Geografía de Wolf. Así, en las primeras páginas del atlas se encuentra una carta de López dirigida al Ministro de Instrucción Pública F. J. Martínez Aguirre, pidiendo el permiso para copiar el mapa geográfico de Teodoro Wolf "que es de propiedad del Estado", con el fin de "[...] facilitar a los niños de las escuelas el estudio de la geografía nacional y de procurar que se conozca mejor el país”. López insiste más tarde que su trabajo trata de corregir " [...] los muchos errores que, en la parte relativa al Ecuador, se han deslizado en las geografías y mapas que circulan con profusión en el extranjero". Así, manifiesta que su pequeño Atlas (el libro tiene tan solo 24 páginas) toma como "[...] base la mejor carta geográfica que ha tenido el Ecuador en estos últimos tiempos, que es la del Dr. Teodoro Wolf, mandada a publicar por orden del Supremo Gobierno en 1892". Sin embargo, resalta la poca funcionalidad que tiene el trabajo de Wolf para la instrucción en las escuelas ya que su carta que fue hecha "con una escala relativamente grande consultando la exactitud" lo cual hizo que se convierta en "[...] un mapa mural magnífico como obra de consulta, pero no adecuado para los escolares”. El Ministro de Instrucción Pública responde a esta petición, concediendo el permiso a López para que "[...] copie el mapa de esta República formado por el Dr. Teodoro Wolf en 1892, y haga las modificaciones que creyere convenientes para que lleve a cabo su fin" $" 85$.

El atlas inicia con tres páginas de generalidades donde se describe los límites, la extensión, la división territorial, la población, las razas, la configuración, los ríos principales, el clima, las producciones, las instituciones y los adelantos. Luego, se divide por provincias, dedicando dos hojas por provincia. La cara izquierda incluye un mapa y la cara derecha incluye texto. En el mapa de la región oriental López mantiene la leyenda de Wolf que atraviesa todo el mapa: "Regiones poco conocidas y habitadas por indios salvajes" $"$. En su descripción de la configuración de la región hace énfasis en el concepto de mar u océano para describir lo desconocido: “[...] esta región extensa del Ecuador está inexplorada todavía en su mayor parte [...] sus selvas gigantescas se extienden cual un océano de verdura, surcado por sus innumerables y

\footnotetext{
${ }^{84}$ López, Felicísimo. Atlas Geográfico del Ecuador, arreglado según la carta del Dr. Teodoro Wolf (American Note Company, 1907).

${ }^{85}$ Ibid, p. 1.

${ }^{86}$ Wolf, T. Carta Geográfica del Ecuador...
} 
grandes ríos" ${ }^{\$ 7}$. El trabajo termina con dos cuadros. Uno de las alturas de montañas y ciudades, y otro sobre la división territorial. Un elemento que llama la atención después de analizar este grupo de catecismos es que Vacas Galindo no aparece en ninguno de estos textos.

Existe una clara traducción o migración del trabajo tanto de Manuel Villavicencio como de Teodoro Wolf hacia los textos escolares, pero la propuesta de Vacas Galindo no aparece a pesar de que Felicísimo López y Roberto Andrade publican después de 1906, año en el que sale a la luz el mapa de Vacas Galindo. ¿Por qué el debate que propone Vacas Galindo no pasa de manera inmediata a las escuelas? ¿Dónde se traduce su propuesta? ¿Se queda acaso únicamente en los círculos diplomáticos? Esta falta de traducción de la tesis de Vacas Galindo puede ser leída, por un lado, como una evidencia de la dificultad que tiene el Estado en manejar una retórica única y uniforme en sus procesos de socialización de la información; y, por otro lado, pone de manifiesto la importancia avasalladora del punto de vista científico de un personaje como Teodoro Wolf en la construcción del espacio.

La falta de migración de la propuesta geográfica de Vacas Galindo llama mucho la atención ya que a inicios del siglo XX la cuestión del espacio era especialmente apremiante para Ecuador dado que su territorio era incierto. Existía una brecha entre el territorio que Ecuador reclamaba como propio y el que los estados vecinos reconocían. Dentro de este contexto, la disputa de límites se convirtió en un problema existencial y el Perú claramente emergió como una amenaza. A diferencia de Wolf, la reflexión de Vacas Galindo sobre el territorio del Ecuador profundiza justamente su dimensión histórica y política. El dominico ve el terreno como un espacio en disputa que es necesario defender. Así, su trabajo introduce una nueva retórica que ya no es estrictamente geográfica sino jurídico-histórico-religiosa. En los ojos de Vacas Galindo, el mapa se convierte en un hecho legal. Esta estrategia le lleva a retomar una continuidad entre la Colonia y la República que no estaba presente en los dos ejercicios cartográficos anteriores. Su análisis se concentra en un momento histórico determinante para entender la relación poder-espacio que se definió a fines de la época colonial y tuvo enormes repercusiones en la constitución de las repúblicas nacientes.

\section{Conclusiones}

Este artículo trata la cuestión de cómo el conocimiento geográfico se articula y circula en el siglo XIX e inicios del siglo XX en Ecuador, a través de la examinación de libros de texto de geografía. A partir de la discusión de Anderson ${ }^{88}$ sobre las bases del nacionalismo, los libros de texto son un espacio a través del cual se discuten y diseminan las imaginaciones geográficas. Su análisis permite hacer una exploración de las maneras en las que el conocimiento geográfico migra o es trasladado desde los geógrafos hacia textos que en principio tienen una mayor posibilidad de circulación. A pesar de que el análisis de este artículo es todavía muy parcial e incompleto, la tesis

\footnotetext{
${ }^{87}$ Ibid.

${ }^{88}$ Anderson, B. Comunidades imaginadas...
} 
que se planteó es que los mapas y los paradigmas propuestos por los tres geógrafos, sus imágenes y sus perspectivas, fueron bien conocidos y circularon dentro de un público educado. En otras palabras, se hicieron parte del discurso público y de la imaginación popular de la nación. Este elemento de circulación de la información geográfica es algo que típicamente no aparece en la mayoría de los trabajos sobre los mapas nacionales y es un ángulo indispensable para vincular el estudio de la geografía con su impacto en la construcción de la nación.

Los distintos niveles de traducción de la información geográfica que se han analizado, muestran la trascendencia de los procesos de aprobación y consentimiento que se llevan a cabo una vez que el territorio ha sido invocado a través del trabajo de los geógrafos. La continua aprobación de una proposición le entrega una autoridad de objeto de referencia y la va separando poco a poco de su autor y de sus condiciones de producción. Así, la autoridad del paradigma propuesto por cada uno de los geógrafos se incrementa a medida que se consolida como fuente de conocimiento. Estas validaciones se repiten miles de veces; cada vez que un profesor enseña geografía en el aula de clases: la información geográfica migra y se convierte en un potente medio para la creación y transferencia de autoridad sobre un territorio y la creación de sujetos nacionales territorializados. Dentro de este contexto, una de las interrogantes que queda abierta para futuras investigaciones tiene que ver con la cuantificación de este proceso. ¿Qué población del país estaría expuesta a esta literatura? ¿Cómo circularon estos textos?

\section{Bibliografía}

\section{Fuentes primarias}

\section{Archivo Aurelio Espinosa Pólit-Quito}

Andrade, Roberto. Lecciones de Geografía para los niños, 2da edición. Guayaquil: Imprenta del Universo, 1899.

Andrade, Roberto. Lecciones de Geografía para los niños, 3ra edición. Guayaquil: Imprenta del Universo, 1902.

Andrade, Roberto. Lecciones de Geografía para los niños, 4ta edición. Guayaquil: Imprenta del Universo, 1903.

Andrade, Roberto. Lecciones de Geografía para los niños, 5ta edición. Guayaquil: Imprenta del Universo, 1904.

Andrade, Roberto. Lecciones de Geografía para los niños, 6ta edición. Guayaquil: Imprenta del Universo, 1905. 
Andrade, Roberto. Lecciones de Geografía para los niños, 7ma edición. Guayaquil: Imprenta del Universo, 1907.

Andrade, Roberto. Lecciones de Geografía para los niños, 8va edición. Guayaquil: Imprenta del Universo, 1910.

Andrade, Roberto. Lecciones de Geografía para los niños, 9na edición. Guayaquil: Imprenta del Universo, 1912.

Andrade, Roberto. Lecciones de Geografía para los niños, 10ma edición. Guayaquil: Imprenta del Universo, 1914.

Andrade, Roberto. Lecciones de Geografía para los niños, 11va edición. Guayaquil: Imprenta del Universo, 1916.

Andrade, Roberto. Lecciones de Geografía para los niños, 12va edición. Guayaquil: Imprenta del Universo, 1918.

Andrade, Roberto. Lecciones de Geografía para los niños, 13va edición. Guayaquil: Imprenta del Universo, 1919.

Andrade, Roberto. Lecciones de Geografía para los niños, 14va edición. Guayaquil: Imprenta del Universo, 1920.

La Condamine, C. M. Carte du cours du Maragnon ou de la grande Riviere des Amazones, dans sa partie navigable despuis Jaen de Bracamoros jusquá son embouchure et qui comprend la Province de Quito et la cote de la Guiane depuis le Cap de Nord jusquá Essequebe levee en 1743 y 1744 et assujettie aux observations astronomiques par M. de la Condamine G. N. Delahaye. (1745).

Magnin, J. Noticias auténticas del famoso río Marañón (1738) seguidas de las relaciones de los P.P. A. de Zárate y J. Magnin (1735-1740). Breve descripción de la Provincia de Quito, en la América meridional, y de sus missiones de Succumbíos de religiosos de S. Francisco, y de Maynas de los PP. de la Compañía de Jesús a las orillas del gran río Marañón, hecha para el mapa que se hizo el año 1740, por el P. Juan Magnin, de dicha Compañía, missionero en dichas missiones. M. Amazónica, Peru: IIAP-CETA, 1988 (1740).

Maldonado, P. V. Carta de la provincia de Quito y de sus adyacantes, obra posthuma de Don Pedro Maldonado, [...] hecha, sobre las observaciones astronómicas y geográficas de los Académicos reales de las ciencias de Paris, y de las guardias Mars de Cadis y también de los RR. PP. missioneros de Maynas, en que la costa desde la boca de Esmeraldas hasta Tumaco con la derrota de Quito al Marañon por una sonda a pie de Baños a Canelos, y el curso de los ríos Bobonaça y Pastaça van delineados sobre las propias demarcaciones del difunto autor Paris, Guill. Delahaye. 
El mapa nacional en el aula de clase: Políticas de memoria...

\section{Libros}

Fritz, S. El gran río Marañón o Amazonas con la misión de la Compañia de Jesús. Geográficamente delineado por el P. Samuel Fritz misionero continuo en este río. Quito, 1707.

Hermanos de las escuelas cristianas. Geografía de la República del Ecuador arreglada por los Hermanos de las Escuelas Cristianas para el uso de sus alumnos. Guayaquil: Imprenta de Calvo, 1881.

Hermanos de las escuelas cristianas. Geografía infantil, Nociones de Geografía física y política por los Hermanos Cristianos para el uso de sus alumnos, 2da edición. Guayaquil: Imprenta de la Nación, 1885.

López, Felicísimo. Atlas Geográfico del Ecuador, arreglado según la carta del Dr. Teodoro Wolf, American Note Company, 1907.

Mera, Juan León. Catecismo de geografía de la República del Ecuador. Texto de enseñanza para las escuelas ecuatorianas, adoptado por el Supremo Gobierno en 1874, Segunda edición, Corregida y aumentada notablemente y hecha con autorización del mismo Supremo Gobierno. Guayaquil: Imprenta de La Nación, 1884.

Mera, Juan León. Catecismo de geografía de la República del Ecuador. Quito: Imprenta Nacional, 1875.

Mera, Juan León. Cumandá. Ecuador: Libresa, 1985 (1879).

Paz y Miño, L. T. Guía para la historia de la cartografía ecuatoriana, primera exposición geográfica nacional. Quito: Publicaciones del Comité Nacional Pedro Vicente Maldonado, 1948.

Spruce, R. Report of the expedition to procure seeds and plants of the Cinchona Succirubra or Red Bark Tree. London: George E. Eyre and William Spottiswoode, 1861.

Vacas Galindo, E. Mapa geográfico-histórico de la República del Ecuador por el R. P. Fray Enrique Vacas Galindo de la Orden de los Predicadores. Paris: Henry Barrere, 1906.

Villavicencio, M. Geografia de la República del Ecuador. Por Manuel Villavicencio Doctor en medicina y miembro de varias academias científicas. New York: Imprenta de Robert Craighead 81, 83, 85; Centre Street, 1858.

Villavicencio, M. Carta corográfica de la República del Ecuador. Nueva York: Lit. e Imp. de F. Mayer y C, 1858. 
Wolf, T. Carta Geográfica del Ecuador por Dr. Teodoro Wolf, publicada por orden del Supremo Gobierno de la Republica y Trabajada Bajo las Presidencias de los EE. Senores Dr. D.J.M. Placido Caamano y Dr. D. Antonio Flores. Leipzig: Instituto geográfico de H. Wagner \& F. Debes, 1892.

\section{Prensa}

Menten, J. “Escuela Politécnica”, El Nacional, 1871.

\section{Fuentes secundarias}

\section{Libros}

Anderson, B. (1993). Comunidades imaginadas: Reflexiones sobre el origen y la difusión del nacionalismo. México: Fondo de cultura, 1993.

Ayala Mora, E. (ed.). Nueva Historia del Ecuador. Quito: Corporación Editora Nacional/Editorial Grijalbo Ecuatoriana, 1990.

Craib, R. Cartographic Mexico: a history of state fixations and fugitive landscapes. London: Duke University Press, 2004.

Díaz Ángel, S. Contribuciones a la historia de la cartografía en Colombia: una red de investigadores y un caso de estudio. Bogotá: Universidad Nacional de Colombia, 2008 .

Dym, J. y Offen, K. Mapping Latin America: a cartographic reader. USA: University of Chicago Press, 2011.

Espinosa, C. Historia del Ecuador en contexto regional y global. España: Lexus editores, 2010.

Harley, J. B. La nueva naturaleza de los mapas: ensayos sobre la historia de la cartografia. Baltimore: He John Hopkins University Press, 2005.

Radcliffe, S. y S. Westwood. Remaking the nation: place, identity and politics in Latin America. London: Routledge, 1996.

Pickles, J. A history of spaces: cartographic reason mapping and the geo-coded world. London: Routledge, 2004.

Sevilla, A. El Ecuador en sus mapas: Estado y nación desde una perspectiva espacial. Ecuador: FLACSO, 2013.

Sparke, M. In the Space of Theory: Postfoundational Geographies of the NationState. USA: University of Minnesota Press, 2005. 
El mapa nacional en el aula de clase: Políticas de memoria...

Vallejo, R. 1., Mera, Juan León y Araujo, D. Historia de las literaturas del Ecuador, Literatura de la República 1830-1895, vol. III. Ecuador: Corporación editora nacional y Universidad Andina Simón Bolívar, 2002.

Villavicencio, M. Geografía de la República del Ecuador. Quito: Corporación editora nacional, 1984 (1858).

Wolf, T. Geografía y Geología del Ecuador por Teodoro Wolf. Quito: Editorial Casa de la Cultura, 1975 (1892).

\section{Capítulos de libros}

Cuvi, N., Sevilla, A., et al. "Entre Darwin y Dios: las primeras clases universitarias sobre el origen de las especies dictadas en el Ecuador (1871)", en Puig-Samper F. O., Miguel Ángel; Ruiz, Rosaura y Uribe, J. Alfredo, «YAMMERSCHUNER». Darwin y la darwinización en Europa y América Latina. Madrid: Ediciones Doce Calles, 2015.

Maiguashca, J. "El proceso de integración nacional en el Ecuador: el rol del poder central 1830-1895”, en Maiguashca, J., Historia y región en el Ecuador: 1830-1930. Ecuador: Proyecto FLACSO-CERLAC IV Corporación Editora Nacional, 1994.

Radcliffe, S. "Imagining the State as Space: Territoriality and the Formation of the State in Ecuador", en States of Imagination: Ethnographic Explorations of the Postcolonial State. T. B. H. y. F. Stepputat. Durham: Duke University Press, 2001.

Radcliffe, S. "Third Space, abstract space and coloniality: National and subaltern cartography in Ecuador", en Postcolonial Spaces: The politics of place in contemporary culture. A. T. a. S. Upstone. London: Palgrave, 2011.

Sevilla, A. "Ciencia y nacionalismo en la construcción del primer mapa del Ecuador", en Políticas de la Memoria y Descolonización en el Ecuador Bicentenario (18092009). Ecuador, Quito: Proyecto Bicentenario FLACSO, 2010.

Terán, F. "La geografía del Ecuador del Dr. Manuel Villavicencio”, en Villavicencio, M., Geografía de la República del Ecuador. Quito: Corporación Editora Nacional, 1984.

\section{Artículos en revistas}

Appelbaum, N. "Reading the Past on the Mountainsides of Colombia: Mid-NineteenthCentury Patriotic Geology, Archaeology, and Historiography", en Hispanic American Historical Review, vol. XCIII, núm. 3, 2013.

Akerman, D. "The Structuring of Political Territory in Early Printed Atlases", en Imago Mundi, vol. XLVII, 1995. 
Capello, E. "Cartógrafos y clérigos. Misiones geodésicas y religiosas en el conocimiento geográfico del Ecuador (Siglos XVIII-XX)", en Araucaria. Revista Iberoamericana de Filosofía, Política y Humanidades, vol. XII, núm. 24, 2010.

Cardona, P. "La nación de papel: Textos escolares, política y educación en el marco de la reforma educativa de 1870”, en Co-herencia, vol. IV, núm. 6, 2007.

Lois, C. "Técnica, política y 'deseo territorial' en la cartografía oficial de la Argentina (1852-1941)”, en Scripta Nova: revista electrónica de geografía y ciencias sociales, vol. X, núm. 52, 2006.

Padron, R. "Cumandá and the cartographers: nationalism and form in Juan León Mera”, en Annals of Scholarship, vol. XII, núms. 3-4, 1998.

Petchenik, B. "The natural history of the atlas: evolution and extinction", en Cartographica, vol. XXII, núm. 3, 1985.

Radcliffe, S. "National maps, digitalisation and neoliberal cartographies: Transforming nation-state practices and symbols in postcolonial Ecuador", en Trans. Institute of British Geographers, vol. XXXIV, 2009.

Radcliffe, S. "Re-Mapping the Nation: Cartography, geographical knowledge and Ecuadorian multiculturalism", en Journal of Latin American Studies, vol. XLII, núm. 2, 2010.

Sánchez Cabra, E. “Agustín codazzi y el descubrimiento de San Agustín”, en Boletín de Historia y Antigüedades, vol. C, núm. 857, 2015.

Sevilla, A. "La incompleta nacionalización de la amazonía ecuatoriana en el siglo XIX vista desde el mapa de Theodor Wolf (1892)", en Apuntes. Revista de estudios sobre patrimonio cultural, vol. XXVI, núm. 1, 2013. 